\title{
Open-Identity Sperm Donation: How Does Offering Donor-Identifying Information Relate to Donor-Conceived Offspring's Wishes and Needs?
}

\author{
An Ravelingien • Veerle Provoost • Guido Pennings
}

Received: 30 January 2014 / Accepted: 8 May 2014 /Published online: 5 July 2014

C) Springer Science+Business Media Dordrecht 2014

\begin{abstract}
Over the past years, a growing number of countries have legislated open-identity donation, in which donor-conceived offspring are given access to the donor's identity once the child has reached maturity. It is held that donor anonymity creates identity problems for such children similar to the "genealogical bewilderment" described within the adoption context. The study of the social and psychological effects of open-identity donation is still very much in its infancy, but what has been left unquestioned is whether (and to what extent) offering access to the donor's name and address is an adequate response to such effects. This study has two goals: First, we aim to provide a systematic review of the reasons why donor-conceived (DC) offspring want to know the identity of their sperm donor. Second, we examine to what extent the provision of donoridentifying information can satisfy the reasons mentioned. The most important motivations appear to be: (1) to avoid medical risks and consanguineous relationships; (2) to satisfy curiosity; (3) to learn more about the self or to complete one's identity; (4) to learn more about what kind of person the donor is (biographical information, why he donated, etc.); (5) to form a relationship
\end{abstract}

\footnotetext{
A. Ravelingien $(\bowtie) \cdot$ V. Provoost $\cdot$ G. Pennings

Bioethics Institute Ghent, Department of Philosophy and Moral Sciences, Ghent University,

Blandijnberg 2, 9000 Ghent, Belgium

e-mail: an.ravelingien@ugent.be

V. Provoost

e-mail: veerle.provoost@ugent.be

G. Pennings

e-mail: guido.pennings@ugent.be
}

with the donor and/or his family; and (6) to learn about one's ancestry/genealogy. Our analysis shows that for nearly all of these reasons access to the donor's identity is not necessary. In those cases where it is, moreover, donor identification is not sufficient. What is really needed is (extended) contact with the donor, rather than the mere provision of his name.

Keywords Donor conception - Open-identity donation . Donor searching · Donor-conceived offspring · Identity

\section{Introduction}

In the context of gamete donation, an ongoing discussion has been whether or not donors should be anonymous to the receivers and their offspring. Over the past 10 to 15 years, a growing number of countries have legislated open-identity donation, in which donorconceived (DC) offspring are given access to the donor's identity once they have reached maturity. This is the case, for instance, in Sweden, Norway, Austria, Switzerland, The Netherlands, the United Kingdom, New Zealand, and Victoria and Western Australia (Pennings 2002). A number of developments have led to the underlying conviction that DC children have a right to know the identity of their gamete donor. Most important in this respect has been the view expressed by professionals and DC offspring themselves that withholding information about the gamete donor is deceptive and potentially harmful to the children. It is held that donor anonymity creates identity problems for DC 
children similar to the "genealogical bewilderment" described within the adoption context (see, for instance, McWhinnie 2001; Chestney 2001; Cahn 2011). This term, as coined by Wellisch in 1952, refers to lack of knowledge, or uncertain knowledge, of at least one genetic parent, which is said to cause a state of confusion and to undermine one's sense of security and concept of self (Sants 1964).

There is still controversy over the shift to openidentity donation. Initially, the debate centred around the concern that open-identity contracts would discourage people from donating and impede sufficient donor supply (Craft and Thornhill 2005). Another topic of debate has been whether a "right to know one's genetic parents" exists (Fortin 2009; Ravitsky 2010) and to what extent this should be balanced against other(s') rights. Increasingly, attention also has been drawn to empirical evidence for the argument that donor anonymity produces psychological and social harm for DC offspring. The child's welfare requirements are a prime concern for policy-makers (McMillan 2014). The study of the social and psychological effects of open-identity donation is still very much in its infancy, but what has been left unquestioned is whether (and to what extent) offering access to the donor's name and address - as is currently the case in open-identity policies - is the appropriate response to such effects. In other words, the connection between DC offspring's needs and the role of identifying donor information is rarely made explicit.

This study has two goals: First, we aim to provide a systematic review of the reasons why some DC offspring want to know the identity of their sperm donor. For this purpose, we review and analyse the published empirical data on DC offspring's reasons for wanting to know their (sperm) donor. Second, we examine to what extent the provision of donor-identifying information can satisfy the reasons mentioned.

\section{Methods}

We conducted a PubMed search (last search on November 27, 2013) using the following search terms: (donor conception OR insemination) AND (donor offspring OR children) AND (contact OR experiences OR search OR identity). This query gave 178 results. We included all English, peer-reviewed publications that presented empirical data on DC offspring's stated reasons for wanting to know (more about) their sperm donor. Excluded were studies that did not report empirical results (opinion papers, ethics statements, etc.) and studies that focused on the parents' rather than the offspring's perspective. A total of 10 studies that fulfilled our inclusion criteria were reviewed (Beeson, Jennings, and Kramer 2011; Jadva et al. 2009, 2010; Hertz, Nelson, and Kramer 2013; Mahlstedt, LaBounty, and Kennedy 2010; Rodino, Burton, and Sanders 2011; Scheib, Riordan, and Rubin 2005; Turner and Coyle 2000; Vanfraussen, Ponjaert-Kristoffersen, and Brewaeys 2001, 2003).

\section{Reasons for Wanting to Know the Identity of One's Sperm Donor}

One of the first studies that examined DC offspring's experiences of their conception was a qualitative study conducted by Turner and Coyle (2000). Of the 16 adult DC offspring recruited via donor conception support networks, 15 felt they had a right to know their genetic origins. Of interest to them was information about the donor's health, appearance, personality, temperament, and genetic traits. In the absence of concrete information, the authors noted a recurring tendency to fantasise about the donor. Two respondents were very explicit in phrasing the feeling that their identity was threatened by lack of identifiable donor information and tied their notion of identity with family and genetic history.

Vanfraussen, Ponjaert-Kristoffersen, and Brewaeys (2001) interviewed 41 children and adolescents (aged 7-17) in Belgium born to lesbian two-parent families. More than half preferred no contact or additional information about the donor. The others did want to know the donor's identity, the most salient motive being curiosity about his physical appearance. Five respondents also were interested in his personality; two wanted to know why he donated; and other information requests (the donor's age, birthday, occupation, hobbies, and whether he was still alive) were each mentioned only once. In a subsequent publication on the same data, Vanfraussen, Ponjaert-Kristoffersen, and Brewaeys (2003) reported that, of the children who did want to know their donor's identity, the majority also wanted to meet him in the hope to find out more about themselves. However, the authors noted that the issue did not seem vitally important to them. Only two donor-identity seekers spoke in terms of a father-child relationship. 
In a study of adolescent offspring with open-identity donors $(n=29)$, Scheib, Riordan, and Rubin (2005) found that 86 percent of the participants were curious about their donor, commonly wanting more information about "what the donor is like" in terms of character traits (83 percent) or appearance (41 percent). Others had questions about his family, whether they share any type (s) of resemblance with the donor, questions pertaining to his health and reasons for donating, and whether he ever thinks about and/or is open to meeting his DC offspring. The majority planned on contacting the donor when reaching 18 , and the most wanted type of information was a picture of the donor, information about his current life circumstances, and information about what he is like. Other findings included: 67 percent of the respondents hoped that contact with the donor would help them learn more about themselves; half hoped to have some type of relationship with him; 62 percent hoped to meet not only the donor, but also his family; 21 percent had not really thought about their donor and had no feelings about him; and 17 percent did not care about him.

Jadva et al. (2009) conducted a survey on a large group of adult and adolescent DC offspring $(n=165)$ recruited via the Donor Sibling Registry, a U.S. online registry created to facilitate contact between donor gamete recipients and offspring with the same donor. The respondents were asked how they felt about being donor conceived. The most common response (69 percent) was "curiosity" (Jadva et al. 2009, 1912). In subsequent research on the same study sample, Jadva et al. (2010) reported that 15 percent of the respondents were searching for their donor siblings; 13 percent were looking for the donor; and 64 percent were searching for both. Among the reasons for wanting to find their donor, curiosity about the characteristics of the donor was most commonly mentioned ( 89 percent), followed by "wanting to meet the donor" (16 percent), and "medical reasons" (12 percent) (Jadva et al. 2010, 528). The interest in information about the donor and donor relations was often prompted by life events such as becoming a teenager or adult, getting married, and becoming a parent. In the study's open-ended questions, there was an emphasis on the importance of knowing one's genetic or ancestral history, not only for themselves but also for their own children.

In 2010, Mahlstedt, LaBounty, and Kennedy published the results of their online survey of adult DC offspring $(n=85)$ recruited via several online support networks. Of their respondents, 76 percent said they wanted to meet, access identifying information, or develop a relationship with their donors. Of this group, a majority referred to the donor as "biological father." They also found it important that they meet halfsiblings or the donor's family.

In a survey of Australian recipients, donors, and DC offspring, Rodino, Burton, and Sanders (2011) questioned the importance of different types of biographical donor information: name, date of birth, photo/age/health/physical characteristics/job/educational level at time of donation, family, donor motivation and times donated, hobbies and interests, cultural and religious background, and feelings regarding contact with the offspring. They found that the DC offspring $(n=23)$ regarded all these types of information as important or very important. The participants' reasons for having chosen certain items as important included: "the importance of family ties $(n=5)$, a sense of incomplete self-identity $(n=3)$, the importance of genetic connectedness $(n=3)$ and a need to satisfy curiosity and a sense of uncertainty/fear of serendipitous encounters with donor-conceived siblings $(n=3)$ )" (Rodino, Burton, and Sanders 2011, 307-308). For two respondents, the information was also deemed of significance for their own children. A particular interest in one's genealogical origins was emphasised by the authors.

In the largest questionnaire with DC offspring to date $(n=741)$, Beeson, Jennings, and Kramer (2011) found that, of those who responded to the question $(n=518)$, 82 percent desired to someday be in contact with their donor. The most frequently reported reason for wanting contact was curiosity about the donor's looks. Other reported reasons were: "To learn about ancestry," "To learn about medical history," "So donor can learn about respondent," and "To establish a relationship with the donor" (Beeson, Jennings, and Kramer 2011, 2420). The authors concluded that a major reason for DC offspring wanting to know more about their donor was to find out more about themselves.

In a recent publication, Hertz, Nelson, and Kramer (2013) reported their findings after analysing the responses of 314 DC offspring, aged 13 or older, from both heterosexual and lesbian two-parent families. They found that 83 percent of the respondents wanted to contact the donor; 38 percent of this group wanted to have a relationship with him; and more than half wanted to be known by the donor. The most frequently given reasons for wanting contact were: "to see what the donor 
looks like (93\%), to learn about the self ( $85 \%$ ), to learn about one's ancestry ( $81 \%)$, and to learn information relevant to one's health (78 \%)" (Hertz, Nelson, and Kramer 2013, 56). Even minimal contact was thought to be helpful in order to better understand themselves.

In sum, there are various recurring reasons for wanting to know one's sperm donor. Given the findings of these studies, the most important motivations would appear to be (in no particular order): (1) to avoid medical risks and consanguineous relationships; (2) to satisfy curiosity; (3) to learn more about the self or to complete one's identity; (4) to learn more about what kind of person the donor is (biographical information, including his social/cultural background, why he donated, etc.); (5) to form a relationship with the donor and/or his family; and (6) to learn about one's ancestry/genealogy.

\section{Relation Between These Reasons and Providing the Donor's Identity}

In 2012, Blyth et al. (2012) published a systematic review of empirical studies on the (broad) experiences of DC offspring. Amongst their conclusions, the authors state that there is consistent evidence that DC people have an interest in information about their genetic and biographical origin and that donor-conception policies should therefore promote transparency and openness and make identifiable donation mandatory. Our review too shows that there is a group of DC offspring who want to know (more) about their donor. Yet, we are hesitant to draw the same conclusion as Blyth and colleagues. Our hesitation relates both to methodological problems of the empirical studies and to unquestioned assumptions about the DC offspring's needs.

One problem with the empirical evidence obtained to date is that the collection of reliable and generalisable data has proven to be very challenging. This is due to the fact that many DC offspring cannot be consulted as they have not been told about their conception status. Moreover, the research participants are typically recruited from support networks, which in itself carries a risk of selection bias: Only those offspring who want to know their donor and/or are willing to share their reasons and concerns in public platforms are included in research (Ravitsky and Scheib 2010). As such, there is little information about the views of those who cannot be reached. Nonetheless, even from the data we have reviewed here (Mahlstedt, LaBounty, and Kennedy
2010; Scheib, Riordan, and Rubin 2005; Vanfraussen, Ponjaert-Kristoffersen, and Brewaeys 2001, 2003), it is clear that not all DC offspring are in fact interested in more information about their donor. Moreover, a longitudinal perspective on DC offspring's experiences is lacking because the first generation of offspring within open-identity donation policies is still relatively young (except for Sweden, but to our knowledge no Swedish data on the psychological and social effects of openidentity donation on offspring is available).

Regardless of this, however, the studies conducted so far do not show directly that the use of identifiable donors is in fact the only and best solution for what these DC offspring want. For one, they do not distinguish between valid needs and needs or wishes based on (genetic) misconceptions (Ravelingien, Provoost, and Pennings 2013). Two, they do not show to what extent transparency and openness actually fulfil these different needs or wishes. In fact, for most of the motivations noted in the studies above, providing donor-identifying information may be helpful, but it is neither necessary nor sufficient.

\section{(1) To Avoid Medical Risks and Consanguineous Relationships}

As for the need to avoid medical risks, anonymous donation policies have various measures at hand that can reduce genetic health risks (screening procedures) and allow medical information to be passed on anonymously (for instance, via the fertility centre). Also, while it has been shown that (for anonymous donor conception) the risk of consanguineous relationships between half-siblings is actually very small (Janssens 2003), this risk can be further reduced through donor registration, by limiting the number of children per donor, or by giving recipients a donor code or number. Knowing the name of the donor is therefore not necessary. It is also not sufficient: Even if offspring were to contact their donors, what guarantee do they have that the donors will always be willing to share all relevant information about their medical history or health risks?

\section{(2) To Satisfy Curiosity}

The fact that the respondents of most of the empirical studies are above all curious about their donor does not 
seem like a strong reason to grant them a right to donoridentifying information. In fact, the argument of harm does not apply: Lack of donor-identifying information will not have a negative effect on them. Moreover, the curiosity most often involves a wish to examine resemblances (in character and appearance) with their donor and to be able to pinpoint which characteristics have been inherited from the mother, which are from the donor, and which are unique to the individual. It is not clear why one needs to access the donor's identity for these purposes. Here, too, a lot can be derived from anonymous information, particularly from extended donor profiles that contain childhood pictures, descriptions of the donor's physical characteristics, ethnic origin, IQ, accomplishments, skills, personality, and other aspects thought to be genetically relevant. On the other hand, a thorough investigation of and comparison with the donor's traits is only really possible if donor and DC offspring meet and compare themselves with each other. Open-donation policies do not guarantee such a form of interaction: That the donor, at the time of donation, is willing to share his identity does not necessarily mean that he will accept to meet the DC offspring so many years later.

\section{(3) To Learn More About the Self or to Complete One's Identity}

This is perhaps the most intuitively compelling reason for supporting DC offspring's search for their donor. However, all of the studies we reviewed presented this "identity argument" - as one might call it —in a very vague way. There is no explanation of why the input of donor information is deemed important for the offspring's identity and which concept of identity underlies these assumptions. Based on the vague descriptions of the findings above, one could interpret that DC offspring hope to find more about "why I am the way I am." This relates to the above-mentioned common curiosity about the biological origin of certain characteristics. Another interpretation is that DC offspring do not only want to know their donor to find out why they are a certain way, but also to help discover who they are. The idea seems to be that they need to know the donor to help uncover hidden parts of oneself or to verify one's assumed talents, traits, and capabilities. According to Velleman, one's biological relatives are the closest thing to a mirror that one can find (Velleman 2005), and " [t]hose who do not know their parents can only wonder who they are becoming" (Velleman 2008, 260). The idea may thus be that the donor is a necessary reference point for investigating shared traits and interests and inferring how one's own future may unfold and be put to best use: a "road map" for life, so to speak. Again, the question is why this should necessarily involve knowing the identity of the donor. The fact that one biological parent and that side of the genetic family are usually present during the DC offspring's upbringing already provides a useful reference point. Also, as Haslanger (2013) notes, it is clear that mirroring ourselves to a biological relative is not the only route to finding out who we are. In fact, one must already have some sense of self-knowledge prior to such mirroring, enabling us to recognise the similarities and differences in the first place. If the point is to find those characteristics that "inherently" typify you, surely how others perceive you can be clarifying, too. Other relevant information also could be inferred from non-identifying information provided through an extended donor profile as described above. Such information could be granted upon request and updated every so many years. On the other hand, if it is felt that direct and thorough feedback on the genetic contribution of the donor to one's personality and capacities is required, this would again imply a rather intense comparison of characteristics and exchange of experiences for which openidentity policies give no guarantee. Moreover, if such information is thought to be crucial for discovering one's self and for assessing one's potential, access to donor information at age 18 comes rather late (Turkmendag 2012).

\section{(4) To Learn More About What Kind of Person the Donor Is}

For DC offspring who seek fuller background information about the donor, the question is not so much "who is my donor?" but rather "what is he like?"; "where is he from?"; "why did he donate?"; and "what is his story?" This calls for information about the circumstances of the donation and for biographical facts about the donor (and his family). Again, the donor's name and contact details are not sufficient: The donor must be willing to engage in personal information sharing and storytelling with the DC offspring. Moreover, such interaction is possible without the provision of donor-identifying information. Anonymous information that includes a brief overview 
of the donor's life and family situation, ethnicity, marital status, a description of his personality and interests, a goodwill message, motivations for donating, etc., could go a long way.

\section{(5) To Form a Relationship With the Donor and/or His Family}

For those who are looking for some kind of meaningful connection with their donor - particularly those who identify themselves as part of the donor's ("extended") family — knowing their donor's name and address will hardly be satisfying. Apart from cases where one merely wants to express gratitude for the donor's "gift" (which can be done through anonymous interaction, analogous to the ways in which patients commonly express thanks to their organ donor/donor family), what is sought is a mutual acknowledgement of the significance of their "blood tie" and perhaps even a relationship of some kind. Again, such relationships would go beyond what one can expect from a right to donor-identifying information. Particularly risky in this sense is that some DC offspring have unrealistic expectations about their donor. As we saw, some peoplein lack of concrete information about the donor - fantasise about him. It is realistic to assume that, in doing so, they create a particular, romantic image that gives a positive twist to their reality. For such people, finding out who their donor really is can be devastatingly disappointing. Very few reports can be found about unsuccessful encounters between DC offspring and donors, but one DC offspring contributing to a forum on donor anonymity warns us of this risk:

I met my sperm donor and on an emotional level there are no winners. There are expectations even if you know there shouldn't be and they are unrealistic due to the situation. It is natural for a child to wonder whom they came from but when meeting them does not produce the deed seeded [deep seated] expectation, it is disappointing ("Max." 2010).

\section{(6) To Learn About One's Ancestry/Genealogy}

One instance where donor identifying information is both necessary and sufficient is in the wish to access information about one's family history. While the interest in one's genetic family history partly overlaps with the wish to know more about the type of person the donor is (in particular, about his family and social and cultural background) and a similar response could thus be offered here (anonymous background information), in the end, the idea is that a person's genealogy records rightfully belong to him. However, given that many naturally conceived families also lack genealogy records, this is hardly a unique and pressing identity need for DC people.

\section{Conclusion}

In conclusion, for nearly all of the empirically reported reasons behind DC offspring's wish to know their sperm donor, access to the donor's identity is not necessary. In those cases where it is, moreover, donor identification is not sufficient. What is really needed to satisfy the reasons mentioned by DC offspring is (extended) contact with the donor rather than the mere provision of his name. Open-donation policies currently do not guarantee any form of contact. That the donor, at the time of donation, is willing to share his identity does not necessarily mean that he will be willing to meet the DC offspring so many years later. Therefore, it would be more appropriate in the debate to talk about "donor contactability" rather than about "donor identifiability." The remainder of the objectives for which donor identification is both necessary and sufficient - to enable knowledge about one's ancestry and genealogy—lack strength and particularity to be a compelling basis for a right to know one's donor.

Funding We kindly acknowledge the funding by the Special Research Fund of Ghent University.

Declaration The authors report no financial or commercial conflicts of interest.

\section{References}

Beeson, D.R., P.K. Jennings, and W. Kramer. 2011. Offspring searching for their sperm donors: How family type shapes 
the process. Human Reproduction 26(9): 2415-2424. doi:10. 1093/humrep/der202.

Blyth, E., M. Crawshaw, L. Frith, and C. Jones. 2012. Donorconceived people's views and experiences of their genetic origins: A critical analysis of the research evidence. Journal of Law and Medicine 19(4): 769-789.

Cahn, N. 2011. No secrets: Openness and donor-conceived "halfsiblings." The Capital University Law Review 39: 313-343.

Chestney, E.S. 2001. The right to know one's genetic origin: Can, should, or must a state that extends this right to adoptees extend an analogous right to children conceived with donor gametes? Texas Law Review 80(2): 364-891.

Craft, I., and A. Thornhill. 2005. Would "all-inclusive" compensation attract more gamete donors to balance their loss of anonymity? Reproductive BioMedicine Online 10(3): 301-306.

Fortin, J. 2009. Children's right to know their origins - too far, too fast. Child \& Family Law Quarterly 21(3): 336-355.

Haslanger, S. 2013. Family, ancestry and self: What is the moral significance of biological ties? Adoption \& Culture. http:// hdl.handle.net/1721.1/64650. Accessed May 17, 2013.

Hertz, R., M.K. Nelson, and W. Kramer. 2013. Donor conceived offspring conceive of the donor: The relevance of age, awareness, and family form. Social Science and Medicine 86: 5265. doi:10.1016/j.socscimed.2013.03.001.

Jadva, V., T. Freeman, W. Kramer, and S. Golombok. 2009. The experiences of adolescent and adults conceived by sperm donation: Comparison by age of disclosure and family type. Human Reproduction 24(8): 1909-1919.

Jadva, V., T. Freeman, W. Kramer, and S. Golombok. 2010. Experiences of offspring searching for and contacting their donor siblings and donor. Reproductive BioMedicine Online 20(4): 523-532.

Janssens, P.M. 2003. No reason for a reduction in the number of offspring per sperm donor because of possible transmission of autosomal dominant diseases. Human Reproduction 18(4): 669-671.

Mahlstedt, P.P., K. LaBounty, and W.T. Kennedy. 2010. The views of adult offspring of sperm donation: Essential feedback for the development of ethical guidelines within the practice of assisted reproductive technology in the United States. Fertility and Sterility 93(7): 2236-2246.

"Max." 2010. Entry in Chatterbox re: "Should sperm donors have the right to remain anonymous?" Dayton Daily News, November 2. http://mo.daytondailynews.com/o/content/shared-gen/blogs/ dayton/chatterbox/entries/2010/11/02/should_sperm_donors_ have the r.html. Accessed January 30, 2014.

McMillan, J. 2014. Making sense of child welfare when regulating human reproductive technologies. Journal of Bioethical Inquiry 11(1): 47-55.

McWhinnie, A. 2001. Gamete donation and anonymity: Should offspring from donated gametes continue to be denied knowledge of their origins and antecedents? Human Reproduction 16(5): 807-817.

Pennings, G. 2002. An overview of the regulation regarding the collection and provision of information about persons involved in sperm donation in jurisdictions outside the UK. Expert report made for the Human Fertilisation and Embryology Authority and the Secretary of State for Health. http://users.ugent.be/ q genning/ Penningsreportdonorinform.pdf.

Ravelingien, A., V. Provoost, and G. Pennings. 2013. Donorconceived children looking for their sperm donor: What do they want to know? Facts, Views and Vision in ObGyn 5(4): 254-261.

Ravitsky, V. 2010. "Knowing where you come from": The rights of donor-conceived individuals and the meaning of genetic relatedness. Minnesota Journal of Law, Science and Technology 11(2): 655-684.

Ravitsky, V., and J.E. Scheib. 2010. Donor-conceived individuals' right to know. The Hastings Center Bioethics Forum blog, July 20. http://www.thehastingscenter.org/Bioethicsforum/ Post.aspx?id=4811\&blogid=140.

Rodino, I.S., P.J. Burton, and K.A. Sanders. 2011. Donor information considered important to donors, recipients and offspring: An Australian perspective. Reproductive BioMedicine Online 22(3): 303-311.

Sants, H.J. 1964. Genealogical bewilderment in children with substitute parents. The British Journal of Medical Psychology 37: 133-141.

Scheib, J.E., M. Riordan, and S. Rubin. 2005. Adolescents with open-identity sperm donors: Reports from 12-17 year olds. Human Reproduction 20(1): 239-252.

Turkmendag, I. 2012. The donor-conceived child's "right to personal identity": The public debate on donor anonymity in the United Kingdom. Journal of Law and Society 39(1): 58-75.

Turner, A.J., and A. Coyle. 2000. What does it mean to be a donor offspring? The identity experiences of adults conceived by donor insemination and the implications for counselling and therapy. Human Reproduction 15(9): 2041-2051.

Vanfraussen, K., I. Ponjaert-Kristoffersen, and A. Brewaeys. 2001. An attempt to reconstruct children's donor concept: A comparison between children's and lesbian parents' attitudes towards donor anonymity. Human Reproduction 16(9): 2019-2025.

Vanfraussen, K., I. Ponjaert-Kristoffersen, and A. Brewaeys. 2003. Why do children want to know more about the donor? The experience of youngsters raised in lesbian families. Journal of Psychosomatic Obstetrics and Gynecology 24(1): 31-38.

Velleman, J.D. 2005. Family history. Philosophical Papers 34(3): 357-378.

Velleman, J.D. 2008. Persons in prospect. Philosophy \& Public Affairs 36(3): 221-287. 